\title{
Incidence and predictors of treatment-related mortality in paediatric acute leukaemia in El Salvador
}

\author{
S Gupta', M Bonilla ${ }^{2}$, SL Fuentes ${ }^{2}$, M Caniza $^{3,4}$, SC Howard ${ }^{3}$, R Barr $^{5}$, ML Greenberg', R Ribeiro ${ }^{3}$ and L Sung*, \\ 'Division of Haematology/Oncology and Program in Child Health Evaluative Sciences, The Hospital for Sick Children, 555 University Avenue, Toronto, ON, \\ Canada M5GIX8; ${ }^{2}$ Pediatric Oncology, Benjamin Bloom National Children's Hospital, San Salvador, El Salvador, ${ }^{3}$ Pediatric Hematology/Oncology, \\ St. Jude Children's Research Hospital, 262 Danny Thomas Place, Memphis, TN 38 105-3678, USA; ${ }^{4}$ Department of Infectious Diseases, St Jude Children's \\ Research Hospital, Memphis, TN 38105-3678, USA; ${ }^{5}$ Pediatric Hematology/Oncology, McMaster University, I 200 Main Street West, Hamilton, ON, \\ Canada L8N $3 Z 5$
}

Survival rates among children with leukaemia in low-income countries are lower than those in high-income countries. This has been attributed in part to higher treatment-related mortality (TRM). We examined the demographics, treatment, and outcomes of paediatric patients in El Salvador with acute lymphoblastic leukaemia (ALL) or acute myeloid leukaemia (AML) to determine the incidence, causes, and risk factors for TRM. Two trained data managers collected data prospectively; no patients were excluded. Biological, socioeconomic and nutritional predictors were examined. A total of 469 patients with ALL and 78 patients with AML were included. The 2-year cumulative incidence of TRM was significantly higher among children with AML (35.4 $\pm 6.4 \%)$ than those with $\operatorname{ALL}(12.5 \pm 1.7 \% ; P<0.000 \mathrm{I})$. However, the proportion of deaths attributable to the toxicity of treatment did not differ significantly between $\operatorname{AML}(25 / 47,53.2 \%)$ and $\operatorname{ALL}(55 / 107,51.4 \% ; P=0.98)$. Among children with $A L L$, low monthly income $(P=0.04)$ and low parental education $(P=0.02)$ significantly increased the risk of TRM. Among children with $A M L$, biological, socioeconomic, and nutritional variables were not associated with TRM. In this low-income country, toxic death significantly contributes to mortality in both ALL and AML. A better understanding of the effect of socioeconomic status on TRM may suggest specific strategies for patients with ALL.

British Journal of Cancer (2009) I 00, 1026-1031. doi:I0.1038/sj.bjc.6604895 www.bjcancer.com

Published online 17 March 2009

(c) 2009 Cancer Research UK

Keywords: acute lymphoblastic leukaemia; acute myeloid leukaemia; treatment-related death; developing countries

The past four decades have seen steady improvements in treatment outcomes for children with leukaemia. In high-income countries (HICs), overall cure rates of approximately $80 \%$ have been achieved in acute lymphoblastic leukaemia (ALL) (Pui and Evans, 2006). Recent trials in children with acute myeloid leukaemia (AML) also have shown improved outcomes and have resulted in event-free survival (EFS) of approximately 50\% (Stevens et al, 1998; Ravindranath et al, 2005; Creutzig et al, 2006). These advances have been attributed to more efficacious use of antileukaemic agents, intensification of treatment when appropriate, identification of prognostic factors for risk stratification, and improvements in supportive care (Ravindranath et al, 2005; Pui and Evans, 2006).

Unfortunately, these advances in survival have not fully translated into low-income countries (LICs) where EFS is significantly lower than in HICs. Potential reasons for different survival rates include a higher rate of relapse, more abandonment of treatment, and higher rates of treatment-related mortality (TRM) in LICs. Improvements in outcome may be achieved by improving disease control, reducing abandonment, and reducing

*Correspondence: Dr L Sung; E-mail: Lillian.sung@sickkids.ca

Received I October 2008; revised 19 December 2008; accepted 23 December 2008; published online 17 March 2009
TRM. The latter becomes particularly important in LICs where TRM is an important contributor to poor outcomes.

The primary objectives of this study were to determine the incidence and causes of TRM among children with ALL and AML in El Salvador. The secondary objectives were to determine predictors of TRM in the same population and to describe TRM in El Salvador relative to published results in HICs and other LICs.

\section{MATERIALS AND METHODS}

\section{Data source}

Data were obtained from the Pediatric Oncology Networked Database (POND) (http://www.pond4kids.org). POND is an online database for paediatric cancer patient information designed to permit users at multiple locations to store and analyse data that include patient demographics, diagnoses, treatments, and outcomes in a secure environment with stringent control of access and privacy. Although the primary purpose of data collection is to monitor patient outcomes and implement quality improvement initiatives, data also can be extracted without personal identifiers for research. At the paediatric cancer centre in El Salvador, two data managers recorded information about patients and their outcomes in real time through chart abstraction. In El Salvador, as in 30 other countries, information about paediatric oncology 
patients is collected routinely, and includes data on patient demographics, nutrition, socioeconomic status, diagnosis, treatment, complications, and outcomes. A recent audit of POND data quality conducted in Honduras, where a similar data management program is in place, showed that accuracy for basic data fields was 99\% (Ayoub et al, 2007).

\section{Study population}

The patient sample consisted of children with ALL and AML treated at the Benjamin Bloom National Children's Hospital (San Salvador, El Salvador). This is the sole treatment centre for children with cancer in the country, in which approximately 200 new patients are treated a year. We included those aged $0-16$ years at diagnosis who had de novo ALL or AML and were diagnosed between 1 January 2000 and 1 July 2007. Patients with acute promyelocytic and mature B-cell leukaemia were excluded.

Patients with ALL were treated according to the El SalvadorGuatemala-Honduras II protocol, which was based on the St Jude Total XIII (Pui et al, 2004b) and Total XV (Pui et al, 2004a) protocols. Significant modifications included the use of only two risk groups (lower and higher, Table 1), the omission of etoposide,

Table I Patient demographic characteristics by diagnosis

\begin{tabular}{|c|c|c|}
\hline Characteristic & ALL & AML \\
\hline Age in years, median (range) & $5.2(0.0,15.1)$ & $5.5(0.2,15.7)$ \\
\hline Male, $N(\%)$ & $263(56)$ & $40(5 \mathrm{I})$ \\
\hline Initial WBC $\left(\left.10^{9}\right|^{-1}\right)$ median (IQR) & I $1.5(4.5,36.3)$ & $15.8(6.7,56.6)$ \\
\hline Initial haemoglobin $\left(\mathrm{g}^{-1}\right)$, median (IQR) & $69(51,90)$ & $77(50,97)$ \\
\hline \multicolumn{3}{|l|}{ Immunophenotype, no (\%) } \\
\hline B lineage & $421(92)$ & \\
\hline$T$ lineage & $35(8)$ & \\
\hline \multicolumn{3}{|l|}{ FAB classification, N (\%) } \\
\hline MO & & $7(9)$ \\
\hline MI & & $18(24)$ \\
\hline$M 2$ & & $26(34)$ \\
\hline M4 & & $8(11)$ \\
\hline M5 & & $6(8)$ \\
\hline M6 & & $2(3)$ \\
\hline M7 & & $7(9)$ \\
\hline \multicolumn{3}{|l|}{ Risk group, N (\%) } \\
\hline Higher risk & $194(44)$ & \\
\hline Standard risk ${ }^{\mathrm{a}}$ & $250(56)$ & \\
\hline \multicolumn{3}{|l|}{ Parental education, N (\%) } \\
\hline Illiterate & $17(4)$ & $3(4)$ \\
\hline Primary & $290(63)$ & $51(67)$ \\
\hline Secondary & $107(23)$ & $18(24)$ \\
\hline Advanced & $4 \mid(9)$ & $3(4)$ \\
\hline Unknown & $4(1)$ & I ( 1$)$ \\
\hline Hours to travel to clinic, median (IQR) & $2.0(1.0,3.0)$ & $2.0(1.0,3.0)$ \\
\hline $\begin{array}{l}\text { Monthly household income (dollars), } \\
\text { median (IQR) }\end{array}$ & $150(100,250)$ & $150(57,228)$ \\
\hline Body mass index percentile, median (IQR) & $43.2(11.1,81.3)$ & $41.2(10.7,77.8)$ \\
\hline $\begin{array}{l}\text { Triceps skin-fold thickness percentile, } \\
\text { median (IQR) }\end{array}$ & $17.5(2.5,62.5)$ & $37.5(17.5,62.5)$ \\
\hline $\begin{array}{l}\text { Mid-upper arm circumference percentile, } \\
\text { median (IQR) }\end{array}$ & $17.5(2.5,37.5)$ & $17.5(2.5,37.5)$ \\
\hline
\end{tabular}

Abbreviations: $\mathrm{ALL}=$ acute lymphoblastic leukaemia; $\mathrm{AML}=$ acute myeloid leukaemia; $F A B=$ French-American-British; $I Q R=$ interquartile range; $N$, number; $W B C$, white blood cell count; . 'Standard risk was defined as DNA index $\geqslant 1$. I6, WBC $<50 \times 10^{9} /$, age $>12$ months and $<10$ years, without any of the following: $(\mathrm{I})$ T-cell lineage, (2) CNS leukaemia at diagnosis, (3) testicular leukaemia or (4) bone marrow M3 on day 15 or M2-M3 on day 36. and the administration of high-dose methotrexate as a 3-h infusion at a dose of $2 \mathrm{~g} \mathrm{~m}^{-2}$ for lower risk and $3 \mathrm{~g} \mathrm{~m}^{-2}$ for higher risk patients.

Between January 2000 and December 2006, patients with AML were treated according to the AHOPCA-AML 1999 protocol, which was based on BFM-AML93 (Creutzig et al, 2001). Significant modifications included the treatment of all children as low risk (without stem cell transplantation, which is unavailable in the region), reduction of daunorubicin by $66 \%$, omission of etoposide during induction and intensification, omission of cyclophosphamide during consolidation, use of high-dose cytarabine and mitoxantrone only in patients without response after induction plus consolidation, and reduction of maintenance therapy to 12 months. After January 2007, patients with AML were treated with the AHOPCA-AML 2007 protocol, based on NOPHO-AML 93 (Lie et al, 2003). Significant modifications included induction therapy as per AHOPCA-AML 1999 (BFM-AML93), but with the addition of etoposide.

The oncology unit at the Benjamin Bloom Hospital has 30 inpatient beds: two single rooms and four other rooms with capacity for seven patients in each room. These rooms do not have air filters. Infection control methods include surveillance for nosocomial infections and quality control programs targeting hand washing and central line care. All children with febrile neutropenia are admitted and started on broad-spectrum antibiotics. Vancomycin and ceftazidime are used in patients with hypotension or other signs of sepsis. Antifungal coverage is initiated in the case of persistent fever. Overall $80 \%$ of blood product requests are met expeditiously; the remaining are met within $24 \mathrm{~h}$.

Abandonment of therapy is a significant treatment challenge in LICs, and efforts to prevent abandonment are an important component of care. In El Salvador, social workers contact families who abandon therapy by telephone. When this is not possible, local health providers visit the patient's home and community to encourage the resumption of treatment. As our study focused on TRM rather than all causes of treatment failure, patients who abandoned treatment were censored in the analysis because they were no longer at risk for TRM. In studies of other clinical outcomes, abandonment is generally treated as an event, with a corresponding decrement in the EFS when a patient abandons treatment.

\section{Outcome measures}

Treatment-related mortality was defined as death unrelated to refractory or progressive disease occurring before first remission was achieved, or any death in complete remission. Death in complete remission was defined as any death occurring 42 days or later after diagnosis in patients who achieved remission. These definitions are consistent with those used by others (Christensen et al, 2005; Slats et al, 2005) to facilitate future comparisons across studies.

All cases of TRM were also sub-divided by specific cause of death into four categories as follows: infection, bleeding, organ failure, and metabolic (predominantly tumour lysis syndrome). Non-TRM causes of death (i.e., death from progressive disease) also were recorded.

\section{Potential predictors}

Several variables were examined as potential predictors of TRM. These were categorized as biological, socioeconomic, and nutritional. Biological variables included age, sex, initial cell counts, DNA index (ALL), cell lineage (B precursor vs T-cell immunophenotype for ALL), risk stratification (higher $v s$ standard for ALL), the and French-American-British classification (M5 vs others for AML; Riley et al, 1999). Socioeconomic variables included monthly income, cost and time to travel to clinic, number of family 
members (all continuous variables), parental education (secondary level or greater $v s$ primary level or less), and the presence of a household telephone. If educational achievement differed among caregivers within a family, the maximal achievement was considered for the analysis. Nutritional variables included body mass index percentile, triceps skin-fold thickness percentile, and mid-upper arm circumference percentile. Body mass index percentile was calculated relative to the 2000 growth charts published by the Centers for Disease Control and Prevention (Ogden et al, 2002). Triceps skin-fold thickness provides a measure of fat mass, whereas the mid-upper arm circumference is a measure of lean mass (Sala et al, 2004). These two variables were chosen as they have been previously suggested to be 'gold standard' measures of nutritional status (Sala et al, 2008).

\section{Statistical methods}

The cumulative incidence of TRM was calculated using the Kaplan-Meier method. For this analysis, relapse and abandonment of therapy were censored as competing events with TRM, which was compared between ALL and AML using the log rank

Table 2 Percentage of mortality attributable to treatment and specific causes of death stratified by diagnosis

\begin{tabular}{lccc}
\hline & ALL & AML & P-value \\
\hline Total number of deaths & 107 & 47 & \\
Morality attributable to & & & \\
$\quad$ Treatment, N (\%) & $55(51.4)$ & $25(53.2)$ & 0.98 \\
Disease, N (\%) & $52(48.6)$ & $22(46.8)$ & \\
& & & \\
Specific causes of TRM & $38(70.4)$ & $14(60.9)$ & 0.4 \\
Infection & $10(18.5)$ & $7(30.4)$ & \\
Bleed & $3(5.6)$ & $2(8.7)$ & \\
Organ failure & $3(5.6)$ & 0 & \\
Metabolic & & \\
\hline
\end{tabular}

Abbreviations: $\mathrm{ALL}=$ acute lymphoblastic leukaemia; $\mathrm{AML}=$ acute myeloid leukaemia; TRM $=$ treatment-related mortality. test. The proportion of mortality attributable to treatment in general and to specific causes of death was compared between ALL and AML using the $\chi^{2}$ test or Fisher's exact test as appropriate. Univariate and multi-variable Cox proportional hazards models were used to explore potential predictors of TRM. Variables with a $P$-value $<0.1$ on univariate analysis were examined in the multiple regression models. Statistical analyses were performed using SASPC software (version 8.0; SAS Institute, Cary, NC, USA) or the Statistical Package for Social Sciences for Windows (version 10.1; SPSS, Chicago, IL, USA). Statistical significance was defined as $P<0.05$. The study was approved by the research ethics committees at The Hospital for Sick Children and the Benjamin Bloom National Children's Hospital.

\section{RESULTS}

In the time frame of interest, 547 patients were treated on the protocols, and all were included in the analysis; 469 had ALL and 78 had AML. Demographic data are shown in Table 1. Two- and 5year EFS rates were $67.7 \pm 2.4$ and $47.3 \pm 3.5 \%$ for ALL and $28.3 \pm 5.6$ and $23.6 \pm 5.6 \%$ for AML $(P<0.0001)$. Two- and 5 -year overall survival rates were $79.8 \pm 2.1$ and $61.1 \pm 3.7 \%$ for ALL and $34.9 \pm 6.3$ and $26.8 \pm 6.3 \%$ for AML $(P<0.0001)$. The 2-year cumulative incidence of TRM was $12.5 \pm 1.7 \%$ for ALL and $35.1 \pm 6.4 \%$ for AML $(P<0.0001)$.

There were 107 deaths in the ALL group and 47 in the AML group (Table 2). The proportion of these deaths attributable to treatment was similar to children with ALL (51.4\%) and AML (53.2\%, $P=0.98)$. Similarly, there was no difference in the proportion attributable to the four most common causes of TRM (infection, bleeding, organ failure, and metabolic) by diagnosis.

Table 3 shows the univariate analyses examining predictors of TRM. Among patients with ALL, lower monthly income (hazard ratio (HR) per $\$ 100=0.81 ; 95 \%$ CI: $0.66,0.99 ; P=0.04$, Figure 1 ) and lower parental education $(\mathrm{HR}=0.46,95 \% \mathrm{CI}: 0.23,0.89$; $P=0.02$, Figure 2) significantly increased the risk of TRM. For children whose maximum parental educational achievement was at least secondary school level, the 2-year cumulative incidence of

Table 3 Univariate analysis of biological, socioeconomic, and nutritional variables as predictors for TRM stratified by diagnosis

\begin{tabular}{|c|c|c|c|c|c|c|}
\hline & \multicolumn{3}{|c|}{ ALL } & \multicolumn{3}{|c|}{ AML } \\
\hline & HR & $(95 \% \mathrm{Cl})$ & $P$-value & HR & $(95 \% \mathrm{Cl})$ & $P$-value \\
\hline Age (years) & 0.93 & $(0.85,1.02)$ & 0.13 & 0.99 & $(0.89,1.11)$ & 0.90 \\
\hline DNA index & 0.57 & $(0.20,1.63)$ & 0.29 & & & \\
\hline B-precursor immunophenotype & 0.53 & $(0.26,1.09)$ & 0.08 & & & \\
\hline High-risk group & 0.86 & $(0.50,1.49)$ & 0.60 & & & \\
\hline Initial haemoglobin $\left(\mathrm{gl}^{-1}\right)$ & 0.98 & $(0.91,1.07)$ & 0.70 & 1.01 & $(0.87,1.17)$ & 0.88 \\
\hline \multicolumn{7}{|l|}{ Socioeconomic variables } \\
\hline Hours to clinic & 0.97 & $(0.84,1.11)$ & 0.61 & 1.01 & $(0.73,1.39)$ & 0.96 \\
\hline Cost to travel to clinic & 1.02 & $(0.93,1.11)$ & 0.72 & 1.08 & $(0.79,1.50)$ & 0.62 \\
\hline Income (per \$100) & 0.81 & $(0.66,0.99)$ & 0.04 & 1.04 & $(0.89,1.22)$ & 0.61 \\
\hline Presence of telephone & 0.75 & $(0.41,1.36)$ & 0.34 & 1.04 & $(0.41,2.68)$ & 0.93 \\
\hline Body mass index percentile & 1.00 & $(0.99,1.02)$ & 0.42 & 1.00 & $(0.99,1.02)$ & 0.87 \\
\hline Triceps skin-fold thickness percentile & 1.00 & $(0.98,1.02)$ & 0.86 & 1.02 & $(0.98,1.06)$ & 0.29 \\
\hline Mid-upper arm circumference percentile & 1.01 & $(0.99,1.03)$ & 0.38 & 1.03 & $(1.00,1.06)$ & 0.06 \\
\hline
\end{tabular}

Abbreviations: $\mathrm{ALL}=$ acute lymphoblastic leukaemia; $\mathrm{AML}=$ acute myeloid leukaemia; $\mathrm{BMI}=$ body mass index; $\mathrm{Cl}=$ confidence interval; $\mathrm{HR}=$ hazard ratio; $\mathrm{TRM}=$ treatmentrelated mortality; $\mathrm{WBC}=$ white blood cell count. 
TRM was $7.1 \pm 2.3 \%$. For children whose parental maximal educational achievement was less than the secondary school level (i.e., primary school or illiterate), the 2-year cumulative incidence of TRM was $15.0 \pm 2.3 \%(P=0.02)$. Both higher initial white blood

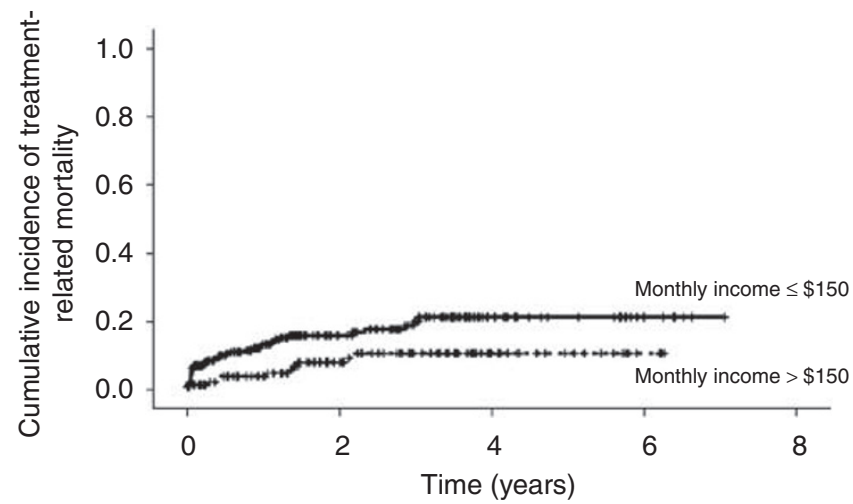

Figure I Cumulative incidence of treatment-related mortality in ALL stratified by monthly family income $>\$ 150$ or $\leqslant \$ 150$.

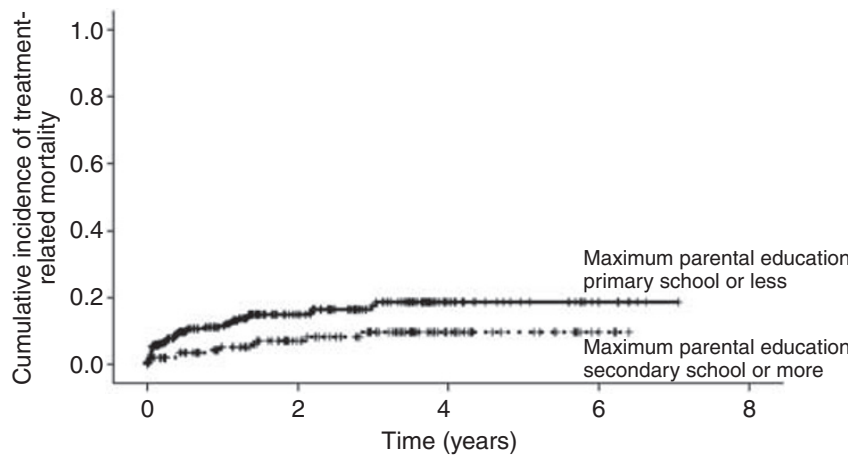

Figure 2 Cumulative incidence of treatment-related mortality in ALL stratified by parental education. cell count $\left(\mathrm{HR}\right.$ per $10 \times 10^{9}$ cells $/ \mathrm{l}=1.00,95 \% \mathrm{CI}: 1.00,1.00$; $P=0.05)$ and non-B precursor immunophenotype $(\mathrm{HR}=0.53$, $95 \%$ CI: $0.26,1.09 ; P=0.08$ ) were non-significantly associated with increased risk of TRM.

As monthly income and parental education were highly correlated (Spearman's correlation coefficient $=0.46, P<0.0001$ ), they could not be examined in the same multiple regression model. When each of monthly income and parental education were placed in multivariable models with initial white blood cell count and B-precursor immmunophenotype, both remained independently predictive of TRM (monthly income adjusted HR per $\$ 100=0.81$, 95\% CI: 0.66, 0.99; $P=0.04$; higher parental education adjusted $\mathrm{HR}=0.47,95 \%$ CI: $0.24,0.91 ; P=0.03)$. In both multivariable models, neither initial white blood cell count nor immunophenotype remained independently predictive of TRM.

Among patients with AML, neither biological, socioeconomic, nor nutritional measures were associated with TRM (Table 3).

Table 4 illustrates our estimates of TRM relative to those shown in HICs and other LICs.

\section{DISCUSSION}

Despite significant reductions in treatment intensity, more than $10 \%$ of children with ALL and about one-third of children with AML die of TRM in El Salvador, which constitutes about half of the deaths in each disease. Finally, lower socioeconomic status is associated with higher TRM in ALL but not in AML.

Our estimates are consistent with those reported in other LICs (Table 4). However, our report is the first to compare the relative contribution of TRM with treatment failure for children with ALL and AML in an LIC. In HICs, TRM accounts for more treatment failure in children with AML than ALL (Christensen et al, 2005; Ravindranath et al, 2005; Slats et al, 2005; Creutzig et al, 2006; Pui and Evans, 2006). Our finding suggests that in LICs, efforts to reduce TRM are as important for children with ALL as for those with AML.

Our study is also unique, as we were able to examine socioeconomic and nutritional variables and their impact on TRM in addition to the traditional biological and clinical factors.

Table 4 Various rates of TRM in ALL and AML in both HICs and LICs

\begin{tabular}{|c|c|c|c|c|}
\hline Reference & Protocol & HIC vs LIC & Country & TRM (\%) \\
\hline \multicolumn{5}{|l|}{ ALL } \\
\hline Christensen et al (2005) & NOPHO ALL92 & $\mathrm{HIC}$ & Nordic & 3.0 \\
\hline Li et al (2003) & HKALL 93 & $\mathrm{HIC}$ & Hong Kong & 2.8 \\
\hline Wheeler et al (1996) & MRCUKALLX & $\mathrm{HIC}$ & United Kingdom & 5.6 \\
\hline Gupta S et al (current) & St. Jude's Modified & LIC & El Salvador & 12.5 \\
\hline Laosombat et al (2002) & Modified CCSG & LIC & Thailand & 11.5 \\
\hline Advani et al (1999) & MCP84I & LIC & India & 16.0 \\
\hline Aziz et al (1997) & Modified BFM & LIC & Pakistan & 14.3 \\
\hline \multicolumn{5}{|l|}{ AML } \\
\hline Creutzig et al (2006) & AML-BFM 98 & $\mathrm{HIC}$ & Various & 7.2 \\
\hline Ravindranath et al (2005) & POG 8821 & $\mathrm{HIC}$ & Various & 14.4 \\
\hline Dluzniewska et al (2005) & PPLLSG 98 & LIC & Poland & 18.0 \\
\hline
\end{tabular}

Abbreviations: $A L L=$ acute lymphoblastic leukaemia; $A M L=$ acute myeloid leukaemia; $H I C=$ high-income countries; $L I C=$ low-income country; $T R M=$ treatment-related mortality. 
Although several studies have examined predictors of TRM in HICs (Wheeler et al, 1996; Riley et al, 1999; Creutzig et al, 2004; Rubnitz et al, 2004; Christensen et al, 2005; Slats et al, 2005), very few have looked at similar risk factors in LICs (Advani et al, 1999). Among patients with ALL in HICs, studies have identified gender, age, high white blood cell count, high-risk ALL, T-ALL, and Down's syndrome as TRM risk factors, although these have not been consistent (Wheeler et al, 1996; Rubnitz et al, 2004; Christensen et al, 2005; Slats et al, 2005). Conversely, Advani et al (1999) found that in the LIC of India, low haemoglobin, lymphadenopathy, and malnutrition were all associated with increased risk of TRM in ALL. They theorised that underlying population biological features as well as more advanced stage at presentation may change the underlying relationships between clinical parameters and TRM.

For children with ALL in El Salvador, in contrast to the abovecited reports in both HICs and LICs, we found that biological factors were not associated with TRM in multiple regression models, and that only poorer socioeconomic status independently predicted TRM. More specifically, only lower household income and lower parental education were associated with higher risk of TRM in ALL. These socioeconomic variables may be proxies for several factors, some of which have been proposed to explain the outcome gap between HICs and LICs (Howard and Wilimas, 2005). These factors include more advanced stage due to delayed presentation and diagnosis, underlying malnutrition, abandonment of treatment (censored in this analysis), delayed recognition of treatment-related complications, or decreased ability to seek prompt medical attention. Initial white blood cell count, measures of malnutrition, and the time and cost of travelling to clinic were not significantly associated with TRM in our study, therefore suggesting that delayed presentation, malnutrition, and distance from the treating facility were not important contributors to TRM in El Salvador. Further research is therefore required to better understand the pathways through which socioeconomic status exerts its negative effect on outcome in ALL.

These findings have implications for future interventions aimed at reducing TRM. Patients of lower socioeconomic status may benefit from more aggressive supportive care in hospital. However, the significant role of socioeconomic status in predicting TRM suggests that further improvements to supportive care may not be as effective in patients with childhood leukaemia as interventions targeting pre-hospital care. Educational efforts aimed at helping parents recognise treatment-related complications may have the greatest impact.
In AML within HICs, female gender, age, high white blood cell count, low performance status at treatment initiation, M5 histology, and the central nervous system status have all been identified as increasing the risk for TRM, although again these findings have varied significantly from study to study (Riley et al, 1999; Creutzig et al, 2004; Rubnitz et al, 2004; Slats et al, 2005). A recent study examining children with AML enrolled on a Children's Cancer Group clinical trial found that age $>16$ years, non-white ethnicity, and underweight status were all significantly associated with infection-related mortality (Sung et al, 2007). We did not find that malnutrition influenced TRM in our study. The difference in the effect of malnutrition between the Children's Cancer Group trial and our data may be related to the differences in treatment, underlying differences in study populations, or lack of power in our study.

Strengths of this study include the population-based nature of its data source; there is only one paediatric oncology treatment centre in El Salvador whose patients are all captured by POND. Another is our ability to examine numerous socioeconomic and nutritional variables in addition to clinical and biological factors. Finally, active community follow-up in cases of abandonment of treatment ensures that cases of mortality are not missed or misclassified. Our report is limited by the relatively small number of children with AML available, thus limiting power in this cohort. In addition, the POND database does not capture those patients who died before reaching the central treatment centre.

Treatment-related mortality was higher in AML than in ALL in this LIC; however, the proportion of mortality attributable to treatment was similar. Socioeconomic factors predicted the risk of TRM within ALL. Future work should include efforts to understand the various pathways through which socioeconomic status may affect TRM and to design and evaluate interventions to reduce TRM in ALL. Multi-centre studies across Central America are needed to better study TRM in AML.

\section{ACKNOWLEDGEMENTS}

LS is supported by the Canadian Childhood Clinician Scientist Training Program, a strategic training program of the Canadian Institutes of Health Research. MLG holds the POGO Chair in Childhood Cancer Control at the University of Toronto. This work was supported in part by the Pediatric Oncology Group of Ontario, the American Lebanese Syrian Associated Charities, and the Fundación Ayúdame a Vivir de El Salvador.

\section{REFERENCES}

Advani S, Pai S, Adde M, Kurkure PK, Nair CN, Sirohi B, Banavali SD, Hawaldar R, Kolhatkar BB, Vats T, Magrath I (1999) Acute lymphoblastic leukemia in India: an analysis of prognostic factors using a single treatment regimen. Ann Oncol 10: 167-176

Ayoub L, Fu L, Pena A, Sierra JM, Dominguez PC, Pui CH, Quintana Y, Rodriguez A, Barr RD, Ribeiro RC, Metzger ML, Wilimas JA, Howard SC (2007) Implementation of a data management program in a pediatric cancer unit in a low income country. Pediatr Blood Cancer 49: $23-27$

Aziz Z, Zahid M, Mahmood R, Maqbool S (1997) Modified BFM protocol for childhood acute lymphoblastic leukemia: A retrospective analysis. Med Pediatr Onc 28: 48-53

Christensen MS, Heyman M, Mottonen M, Zeller B, Jonmundsson G, Hasle $\mathrm{H}$, Nordic Society of Paediatric Haematology and Oncology (NOPHO) (2005) Treatment-related death in childhood acute lymphoblastic leukaemia in the Nordic countries: 1992-2001. Br J Haematol 131: $50-58$

Creutzig U, Ritter J, Zimmermann M, Hermann J, Gadner H, Blutters Sawatzki D, Niemeyer CM, Schwabe D, Selle B, Boos J, Kuhl J, Feldges A, AML-BFM Study Group (2001) Idarubicin improves blast cell clearance during induction therapy in children with AML: results of study AML-BFM 93. Leukemia 15: 348-354

Creutzig U, Zimmermann M, Lehrnbecher T, Graf N, Hermann J, Niemeyer CM, Reiter A, Ritter J, Dworzak M, Stary J, Reinhardt D (2006) Less toxicity by optimizing chemotherapy, but not by addition of granulocyte colony-stimulating factor in children and adolescents with acute myeloid leukemia: results of AML BFM 98. J Clin Oncol 24: 4499-4506

Creutzig U, Zimmermann M, Reinhardt D, Dworzak M, Stary J, Lehrnbecher T (2004) Early deaths and treatment-related mortality in children undergoing therapy for acute myeloid leukemia: analysis of the multicenter clinical trials AML-BFM 93 and AML-BFM 98. J Clin Oncol 22: $4384-4393$

Dluzniewska A, Balwierz W, Armata J, Balcerska A, Chybicka A, Kowalczyk J, Matysiak M, Ochocka M, Radwanska U, Rokicka-Milewska R, SontaJakimczyk D, Wachowiak J, Wysocki M (2005) Twenty years of Polish experience with three consecutive protocols for treatment of childhood acute myelogenous leukemia. Leukemia 19: 2117-2124

Howard SC, Pedrosa M, Lins M, Pedrosa A, Pui CH, Ribeiro RC, Pedrosa F (2004) Establishment of a pediatric oncology program and outcomes of 
childhood acute lymphoblastic leukemia in a resource-poor area. JAMA 291: $2471-2475$

Howard SC, Wilimas JA (2005) Delays in diagnosis and treatment of childhood cancer: where in the world are they important? Pediatr Blood Cancer 44: 303 - 304

Laosombat V, Wongchanchailert M, Sattayasevana B, Wiriyasateinkul A, Watana-Arepornchai S (2002) The treatment of children with acue lymphoblastic leukemia in Thailand. Med Pediatr Onc 38: 266-268

Li CK, Chik KW, Chan GC, Yuen HL, Lee AC, Li CK, Shing MM, Hay SY, Luk CW, Ling SC, Cheung AY, Hong Kong Paediatric Haematology and Oncology Study Group (2003) Treatment of acute lymphoblastic leukemia in Hong Kong children: HKALL 93 Study. Hematol Oncol 21: $1-9$

Lie SO, Abrahamsson J, Clausen N, Forestier E, Hasle H, Hovi L, Jonmundsson G, Mellander L, Guftasson G (2003) Treatment stratification based on initial in vivo response in acute myeloid leukaemia in children without Down syndrome. Results of NOPHO-AML trials. Br J Haematol 122: $217-225$

Metzger ML, Howard SC, Fu LC, Pena A, Stefan R, Hancock ML, Zhang Z, Pui CH, Wilimas JA, Ribeiro RC (2003) Outcome of childhood acute lymphoblastic leukaemia in resource-poor countries. Lancet 362: 706

Ogden CL, Kuczmarski RJ, Flegal KM, Mei Z, Guo S, Wei R, GrummerStrawn LM, Curtin LR, Roche AF, Johnson CL (2002) Centers for disease control and prevention 2000 growth charts for the United States: improvements to the 1977 national center for health statistics version. Pediatrics 109: $45-60$

Pui CH, Evans WE (2006) Treatment of acute lymphoblastic leukemia. $N$ Engl J Med 354: $166-178$

Pui CH, Relling MV, Sandlund JT, Downing JR, Campana D, Evans WE (2004a) Rationale and design of Total Therapy Study XV for newly diagnosed childhood acute lymphoblastic leukemia. Ann Hematol 83: S124-S126

Pui CH, Sandlund JT, Pei D, Campana D, Rivera GK, Ribeiro RC, Rubnitz JE, Razzouk BI, Howard SC, Hudson MM, Cheng C, Kun LE, Raimondi SC, Behm FG, Downing JR, Relling MV, Evans WE (2004b) Improved outcome for children with acute lymphoblastic leukemia: results of Total
Therapy Study XIIIB at St Jude Children's Research Hospital. Blood 104: $2690-2696$

Ravindranath Y, Chang M, Steuber CP, Becton D, Dahl G, Civin C, Camitta B, Carroll A, Raimondi SC, Weinstein HJ, Pediatric Oncology Group (2005) Pediatric Oncology Group (POG) studies of acute myeloid leukemia (AML): a review of four consecutive childhood AML trials conducted between 1981 and 2000. Leukemia 19: $2101-2116$

Riley LC, Hann IM, Wheatley K, Stevens RF (1999) Treatment-related deaths during induction and first remission of acute myeloid leukemia in children treated on the Tenth medical Research Council Acute Myeloid Leukaemia Trial (MRC AML10). Br I Haematol 106: 436 - 444

Rubnitz JE, Lensing S, Zhou Y, Sandlund JT, Razzouk BI, Ribeiro RC, Pui $\mathrm{CH}$ (2004) Death during induction therapy and first remission of acute leukemia in childhood: the St. Jude experience. Cancer 101: 1677-1684

Sala A, Pencharz P, Barr RD (2004) Children, cancer, and nutrition - a dynamic triangle in review. Cancer 100: 677-687

Sala A, Rossi E, Antillon F (2008) Nutritional status at diagnosis in children and adolescents with cancer in the AHOPCA (Asociacion de HematoOncologia Pedatrica de Centro America) Countries. Preliminary results from Guatemala. Pediatr Blood Cancer 50: 499-501

Slats AM, Egeler RM, van der Does-van den Berg A, Korbijn C, Hahlen K, Kamps WA, Veerman AJ, Zwaan CM (2005) Causes of death - other than progressive leukemia - in childhood acute lymphoblastic leukemia (ALL) and myeloid leukemia (AML): the Dutch Childhood Oncology Group experience. Leukemia 19: 537 -544

Stevens RF, Hann IM, Wheatley K, Gray RG (1998) Marked improvements in outcome with chemotherapy alone in paediatric acute myeloid leukaemia: results of the United Kingdom Medical Research Council's 10th AML trial. Br I Haematol 101: 130-140

Sung L, Lange BJ, Gerbing RB, Alonzo TA, Feusner J (2007) Microbiologically documented infections and infection-related mortality in children with acute myeloid leukemia. Blood 110: 3532-3539

Wheeler K, Chessells JM, Bailey CC, Richards SM (1996) Treatment related deaths during induction and in first remission in acute lymphoblastic leukaemia: MRC UKALL X. Arch Dis Child 74: 101-107 